\title{
PENELITIAN ASPEK BUDAYA PADA SISTEM INFORMASI
}

\author{
Riri Satria \\ Fakultas Ilmu Komputer, Universitas Indonesia, Jakarta, Indonesia \\ ririsatria@yahoo.com
}

\begin{abstract}
Abstrak
Tulisan ini diinspirasi oleh keyakinan tentang adanya krisis dalam disiplin ilmu sistem informasi (SI). Pendapat ini muncul karena penelitian mengenai signifikansi peranan SI terhadap keberhasilan menjalankan bisnis atau organisasi sangat sedikit. Padahal SI dianggap sebagai salah satu komponen penunjang keberhasilan dalam menjalankan bisnis atau organisasi. Ini menyebabkan muncul keyakinan terjadinya krisis keilmuan tersebut, [1,2,3]. Penulis menelusuri berbagai hasil penelitian untuk tesis yang dilakukan oleh para mahasiswa Program Magister Teknologi Informasi Universitas Indonesia mengenai SI, dan hasilnya menunjukkan penelitian yang dominan adalah topik aspek manajemen pada SI, serta tentu saja aspek teknis SI itu sendiri. Padahal ada satu aspek yang tidak bisa diabaikan, yaitu aspek budaya pada SI, karena keberhasilan implementasi SI juga ditentukan oleh aspek budaya. Kemudian penulis menelusuri berbagai penelitian aspek budaya pada SI yang dimuat pada Jurnal MIS Quarterly (ada 15 penelitian). Penulis menyimpulkan bahwa terdapat 4 kategori penelitian aspek budaya pada SI, yaitu (1) budaya sebagai input untuk desain dan rencana implementasi, (2) budaya sebagai komponen penentu proses (process) desain dan rencana implementasi, (3) budaya sebagai dampak (outcomes) dari implementasi SI, serta (4) budaya sebagai akselerator (accelerator) untuk pemanfaatan SI secara optimal pasca implementasi.
\end{abstract}

Kata Kunci: Budaya dan Sistem Informasi, Penelitian Bidang Sistem Informasi

\section{Pendahuluan}

Mengapa tulisan ini muncul? Ini disebabkan rasa penasaran penulis melihat berbagai topik penelitian tesis mahasiswa program Magister Teknologi Informasi UI yang sangat banyak menyoroti 2 aspek utama, yaitu (1) aspek manajemen atau organisasi, serta (2) aspek teknis dari TI itu sendiri. Penulis berpendapat bahwa kesuksesan atau optimalisasi pemanfaatan TI di dalam bisnis atau organisasi juga ditentukan oleh aktor yang terdapat di dalam sistem tersebut, yaitu manusia, baik berperan sebagai pengguna (user), pembuat keputusan (decision maker), pengembang (developer, termasuk sebagai designer dan programmer), peneliti (researcher), serta maintenance operator.

Dengan demikian, kita mungkin melupakan satu komponen penting, yaitu aktor, atau manusia tersebut, yang memiliki aspek budaya, karena memang merupakan salah satu komponen dalam sistem budaya (cultural system).

Tulisan ini ingin menunjukkan kepada pembaca bahwa penelitian mengenai aspek budaya pada SI atau TI menjadi signifikan manfaatnya.
Implikasinya adalah, perlu dibuka peluang kepada mahasiswa di program Magister Teknologi Informasi UI untuk meneliti hal ini, karena merupakan salah satu pilar dalam SI yang merupakan bahasan program ini.

\section{Aspek Budaya Pada Sistem Informasi}

Lamb dan Kling [4] berargumen bahwa salah satu aktor terpenting dalam SI adalah pengguna (user). Dengan demikian, penelitian seputar pengguna (user-centered research) di dalam SI akan memberikan kontribusi yang signifikan dalam optimasi manfaat TI. Pengguna itu sendiri memiliki 4 atribut, yaitu afiliasi, lingkungan, interaksi, dan identitas.

Di sisi lain, Alexander [5] menjelaskan bahwa, “... every social object can be analyzed as a cultural object, every social culture as culture structure. Events, actors, roles, groups, and institutions, as elements in concrete society, are part of social system; they are simultaneously, however, part of a cultural system ... Culture is an environment of every action .. Cultural codes, like linguistic languages, are built upon signs, which 
contain both signifier and signified. Technology, for example, is not only a thing, a signified object to which others refer, it is also a signifier, a signal, an internal expectations ... Analytically, however, technology is also part of cultural system. It is a sign, both a signifier and signified, in relation to which actors cannot entirely seperate their subjective states of mind".

Jika dianalisis lebih lanjut, keempat komponen yang diuraikan oleh Lamb dan Kling di atas, sangat relevan dengan definisi budaya yang diajukan oleh Alexander. Pengguna TI adalah aktor dalam suatu sistem yang disebut SI. Sementara itu, menurut argumen Alexander, teknologi (termasuk TI tentunya) juga termasuk ke dalam sistem budaya. Argumen Lamb dan Kling, serta Alexander, jika disintesakan akan membawa kita kepada kesimpulan bahwa TI (dalam lingkup yang lebih luas adalah SI) adalah suatu bagian dari sistem budaya, dan pasti juga sangat dipengaruhi oleh komponen dan norma budaya.

Misalnya, user-centered research dalam SI sebenarnya adalah riset mengenai budaya, karena sesuai dengan argumen Alexander, "actors cannot seperate their subjective states of mind", dan itu adalah suatu komponen budaya.

\section{Berbagai Topik dan Metode Penelitian}

Apa saja yang menjadi topik penelitian aspek budaya pada SI ? Berikut ini adalah hasil kompilasi dari berbagai penelitian yang dimuat pada jurnal MIS Quarterly.

Brown dan Venkatesh [6] meneliti mengenai aspek budaya dalam mengadopsi TI. Ini termasuk ke dalam kategori penelitian budaya sebagai proses. Komponen budaya yang diteliti adalah pandangan mengenai manfaat TI, nilai-nilai normatif yang dianut, serta persepsi diri terhadap kemampuan untuk menguasai teknis penggunaan TI nantinya. Ini mempengaruhi keputusan seseorang terhadap adopsi TI ke dalam organisasinya nanti. Penelitian ini dilakukan dengan metode empiris kuantitatif dengan statistik inferensi.

Ahuja dan Thatcher [7] meneliti mengenai komponan yang mempengaruhi seseorang untuk mengoptimalkan penggunaan TI untuk melakukan inovasi di dalam organisasi atau tempat kerjanya. Penelitian termasuk ke dalam kategori aspek budaya sebagai akselerator. Komponen budaya yang diteliti adalah otonomi dalam pekerjaan, persepsi terhadap beban kerja, serta gender. Penelitian ini dilakukan dengan metode empiris kuantitatif dengan statistik inferensi. Penelitian yang sejenis dilakukan oleh Karahanna, Agarwal, dan Angst [8] dengan fokus kepada komponen persepsi terhadap manfaat serta persepsi terhadap kemudahan penggunaan. Penelitian lainnya yang sejenis juga dilakukan oleh Paul dan McDaniel [9] yang meneliti faktor yang akam membuat pengguna mengoptimal TI sebagai media untuk kolaborasi virtual dalam pekerjaannya. Komponen budaya yang mempengaruhi adalah interpersonal trust yang terdiri dari minat pribadi, kemampuan, rasa empati, serta sikap percaya kepada sistem. Penelitian Karahanna [8] dan Paul [9] juga mengunakan metode empiris kuantitatif dengan statistik inferensi.

Lapointe dan Rivard [10] meneliti mengenai hubungan antara persepsi dampak pasca implementasi TI pada organisasi dengan tingkat perilaku resisten para pihak yang berkepentingan di dalam organisasi terhadap implementasi TI. Penelitian ini termasuk ke dalam kategori aspek budaya sebagai akselerator, di mana pada penelitian ini adalah penghambat akselerasi. Komponen budaya yang diteliti adalah persepsi terhadap status, serta persepsi terhadap kekuasaan. Pada penelitian juga terdapat komponen lain, yaitu komponen manajerial, ekonomi, dan struktur organsiasi. Penelitian ini dilakukan dengan metode interpetif berbentuk case study research yang deskriptif.

Beaudry dan Pinsonneault [11] meneliti bagaimana pengguna TI melakukan penyesuaian diri terhadap TI yang ada pasca implementasi. Ini termasuk ke dalam kategori budaya sebagai dampak implementasi. Komponen budaya yang menjadi fokus penelitian adalah kestabilan emosi pengguna setelah melewati fase perubahan akibat implementasi TI (restoring personal emotional stability), lalu perilaku efektif dan efisien dalam bekerja, serta inisiatif untuk ikut serta meminimalkan dampak negatif pasca implementasi TI. Penelitian ini dilakukan dengan metode interpetif berbentuk case study research yang deskriptif. Penelitian sejenis tentang juga dilakukan oleh Jasperson, Carter, Zmud, [12], tetapi lebih fokus kepada aspek kognitif dari pengguna TI. Begitu juga dengan penelitian Gattiker dan Goodhue [13], di mana ternyata pasca implementasi ERP tidak selalu terbentuk budaya koordinatif antar berbagai pihak di dalam organisasi, walaupun ERP sendiri bertujuan untuk meningkatkan integrasi dan koordinasi.

Penelitian aspek budaya yang komprehensif, di mana semua kategori penelitian, yaitu budaya sebagai input, budaya sebagai proses, budaya sebagai dampak, serta budaya sebagai akselerator, terdapat pada penelitian Feng [14] yang meneliti aspek budaya dalam manajemen SI, yaitu budaya 
Cina. Feng membandingkan dengan hasil penelitian tentang budaya Belanda, maka kesimpulannya terdapat perbedaan signifikan antara manajemen SI dalam konteks budaya Belanda dengan budaya Cina. Penelitian sejenis dalam ruang lingkup yang lebih kecil dilakukan oleh Avgerou dan McGrath [15] yang dilakukan di sebuah organisasi di Yunani. Penelitian Avgerou dan McGrath memiliki fokus kepada komponen budaya kekuasaan, rasionalitas berpikir, serta gaya hidup.

\section{Kesimpulan}

TI atau dalam ruang lingkup yang lebih luas, SI, adalah suatu sistem budaya. Hal ini menyebabkan optimalisasi penggunaan TI juga sangat ditentukan oleh aspek budaya. Dengan demikian, riset mengenai aspek budaya dalam SI atau TI menjadi penting.

Aspek budaya dalam SI atau TI dapat dikategorikan atas 4 kelompok, yaitu (1) budaya sebagai input, (2) budaya sebagai proses, (3) budaya sebagai dampak, serta (4) budaya sebagai akselerator.

Umumnya penelitian mengenai aspek budaya pada SI atau TI masih menggunakan pendekatan empiris atau positivistik yang kuantitatif. Masih sedikit penelitian yang menggunakan pendekatan interpretif, apalagi critical theory. Ini sesuai dengan kondisi yang digambarkan Klein [16] bahwa pendekatan interpretif masih belum sepenuhnya diterima sebagai pendekatan ilmiah dalam penelitian. Sementara itu, critical theory masih berada di dalam ranah ilmu sosial atau budaya murni, belum banyak diadopsi di ranah SI.

\section{Saran}

Penelitian mengenai aspek budaya pada SI atau TI harusnya diterima sebagai salah satu anggota dalam domain keilmuan SI, termasuk di dalam program Magister Teknologi Informasi UI. Tentu saja pendekatannya menjadi lintas disiplin, di mana berbagai pendekatan yang lazim dilakukan dalam ilmu sosial disintesiskan dengan berbagai pendekatan yang lazim pada dunia TI dan manajemen atau organisasi. Secara praktis, ini akan memberikan manfaat kepada upaya-upaya untuk mengoptimalkan manfaat TI sebagai komponen stratejik dalam bisnis atau organisasi. Ini akan memfasilitasi minat mahasiswa yang berasal dari disiplin ilmu sosial untuk ikut serta memberikan kontribusi pemikiran tentang optimalisasi pemanfaat TI di dunia nyata.

\section{REFERENSI}

[1] Agarwal, R., H. C. Lucas, "The Information Systems Identity Crisis : Focusing on HighVisibility and High-Impact Research", dalam : MIS Quarterly, Volume 29, No 3, September 2005 : 381-398, 2005.

[2] Benbasat, I., R. W. Zmud, "The Identity Crisis Within the IS Discipline : Defining and Communicating the Discipline's Core Properties", dalam : MIS Quarterly, Volume 27, No 2, Juni 2003: hlm. 183-194, 2003.

[3] King, J. L., K. Lyytinen, "Reach and Grasp", dalam : MIS Quarterly, Volume 28, No 4, Desember 2004 : hlm. 539-551, 2004.

[4] Lamb, R., R. Kling, "Reconceptualizing Users as Social Actors in Information Systems Research", dalam : MIS Quarterly, Volume 27, No 2, Juni 2003 : hlm. 197-236, 2003.

[5] Alexander, J. C., The Promise of A Cultural Sociology : Technological Discourse and Profane Information Machine, dalam : Munch, R. N. J. Smelser, (1992), Theory of Culture, University of California Press, Berkeley : hlm. 293-323, 1992.

[6] Brown, S. A., V. Venkatesh, "Model of Asoption of Technology in Households : A Baseline Model test and Extension Incorporating Household Life Cycle", dalam : MIS Quarterly, Volume 29, No 3, September 2005 : hlm. 399-426, 2005.

[7] Ahuja, M. K., J. B. Thatcher, "Moving Beyond Intentions and Toward the Theory of Trying : Effects of Work Environment and Gender on Post-Adoption Information Technology Use", dalam : MIS Quarterly, Volume 29, No 3, September 2005 : hlm. 427-460, 2003.

[8] Karahanna, E., R. Agarwal, C. M. Angst, "Reconceptualizing Compatibility Beliefs in Technology Acceptance Research", dalam : MIS Quarterly, Volume 30, No 4, Desember 2006: hlm. 781-804, 2006.

[9] Paul, D. L., R. R. McDaniel Jr, "Field Study of the Effect of Interpersonal Trust on Virtual Collaborative Relationship Performance", dalam : MIS Quarterly, Volume 28, No 4, Juni 2004 : hlm. 183-227, 2004.

[10] Lapointe, L., S. Rivard, "A Multilevel Model of Resistance to Information Technology Implementation", dalam : MIS Quarterly, Volume 29, No 3, September 2005 : hlm. 461-492, 2005. 
[11] Beaudry, A., A. Pinsoneault, "Understanding User Responses to Information Technology : A Coping Model of User Behavior", dalam : MIS Quarterly, Volume 29, No 3, September 2009 : hlm. 493-525, 2005.

[12] Jasperson, J., P. E. Carter, R. W. Zmud, "A Comprehensive Conceptualization of PostAdoptive Behaviors Associated with Information Technology Enabled Work Systems", dalam : MIS Quarterly, Volume 29, No 3, Juni 2005 : hlm. 525-558, 2005.

[13] Gattiker, T. F., D. L. Goodhue, "What Happens after ERP Implementation : Understanding the Impact of Interdependence and Differentiation on Plant-Level Outcomes", dalam : MIS Quarterly, Volume 29, No 3, September 2009 : hlm. 559-585, 2005.
[14] Feng, X., "Information Systems Management and Culture : Experiences from a Chinese Perspectives", $\mathrm{PhD}$ Dissertation, Technische Universiteit Eindhoven, 2003.

[15] Avgerou, C., McGarth, "Power, Rationality, and the Art of Living throught SocioTechnical Change", dalam : MIS Quarterly, Volume 31, Issue 2, Juni 2007 : hlm. 295315, 2007.

[16] Klein, H. K., "A Set of Principles for Conducting and Evaluating Interpretive Field Studies in Information Systems", dalam : MIS Quarterly, Volume 23, No 1, Maret 1999, 1999. 